\title{
UMA PROPOSTA DE PROGRAMAÇÃO DE CONTEÚDO DE ENSINO PARA "ATUALIDADES BRASILEIRAS"
}

Heitor Romero Marques*

\section{INTRODUÇÃO}

A partir de 1993, as Universidades Brasileiras puderam optar por uma nova disciplina, que fosse comum para seus cursos de graduação, em substituição aos Estudos de Problemas Brasileiros. A opção, em particular da Universidade Católica Dom Bosco, recaiu sobre Atualidades Brasileiras (ABR), que passou a ser desenvolvida em dois semestres consecutivos (I e II), com carga horária mínima de $30 \mathrm{~h} / \mathrm{a}$ semestrais.

No estabelecimento da Programação dos conteúdos de ensino surgiu, inicialmente, uma dificuldade, rapidamente transposta, qual seja: se os conteúdos programáticos deveriam ser específicos para cada curso de inclusão ou se seriam comuns a todos os cursos, indistintamente.

* Professor de Atualidades Brasileiras, Metodologia do Trabalho Científico e Filosofia da Educação, na UCDB; Especialista de Educação na rede pública de ensino de MS. Graduado em Ciências, licenciado em Pedagogia, especializado em Filosofia e História da Educação e cursa o programa de Mestrado em Educação da UCDB. 
A solução adotada veio do raciocínio de que as questões nacionais são comuns a todos os cidadãos e, por conseguinte, a todos os cursos da Universidade. Daí a proposta ser a de uma abordagem com ênfase específica para cada curso (em vista de seus objetivos), a partir de um tronco comum de conhecimento.

A nova disciplina passou a ter como objetivo definido: propiciar ao acadêmico oportunidade de formação na cidadania, pela análise crítica da atualidade, na perspectiva de uma sociedade social e economicamente justa e da busca do Estado democrático.

A característica da programação (expressa no Mapa Conceitual) é observar a diferenciação progressiva, isto é, uma seqüenciação de conceitos, que obedeça ao critério da maior à menor generalidade, inclusividade e estabilidade e observa a reconciliação integrativa que, além de buscar a unidade de todo o conjunto de conceitos, busca também uma análise da consistência entre esses conceitos, discriminando semelhanças e diferenças entre eles.

\section{PRIMEIRA UNIDADE: CIDADANIA}

Nesta primeira unidade, obedecendo-se a uma visão de globalidade, pretende-se a construção de conceitos referentes ao significado de cidadania e à identificação dos meios de atingimento dessa cidadania, quais sejam: a organização do Estado Brasileiro, Políticas Públicas, Educação e Desenvolvimento Sócio-Econômico, que deverão 
sofrer diferenciações progressivas no decorrer do curso.

\section{SEGUNDA UNIDADE: ORGANIZAÇÃO DO ESTADO BRASILEIRO}

Nesta segunda unidade, pretende-se a conceituação de Organização do Estado Brasileiro (enquanto meio que surge da diferenciação do conceito de cidadania) pela análise do professor e elaboração pelos alunos dos conceitos básicos referentes à Teoria do Estado e de Política, nas dimensões de sociedade, nação, regimes e formas de governo, soberania, ideologia e partidos políticos. A assimilação de tais conceitos permitirá o entendimento do significado de Estado Soberano e Democracia e, conseqüentemente, cidadania.

\section{TERCEIRA UNIDADE: EDUCAÇÃO}

Nesta unidade, pretende-se conceituar educação enquanto meio de promoção e atingimento da cidadania (conceito síntese da programação) e, em vista de sua importância, será analisada sob os aspectos: direito à educação e demanda, realidade educacional brasileira, investimento e financiamento, parâmetros internacionais, que serão integralizados na abordagem sobre o Plano Decenal de Educação.

O aprofundamento conceitual do Plano Decenal de 


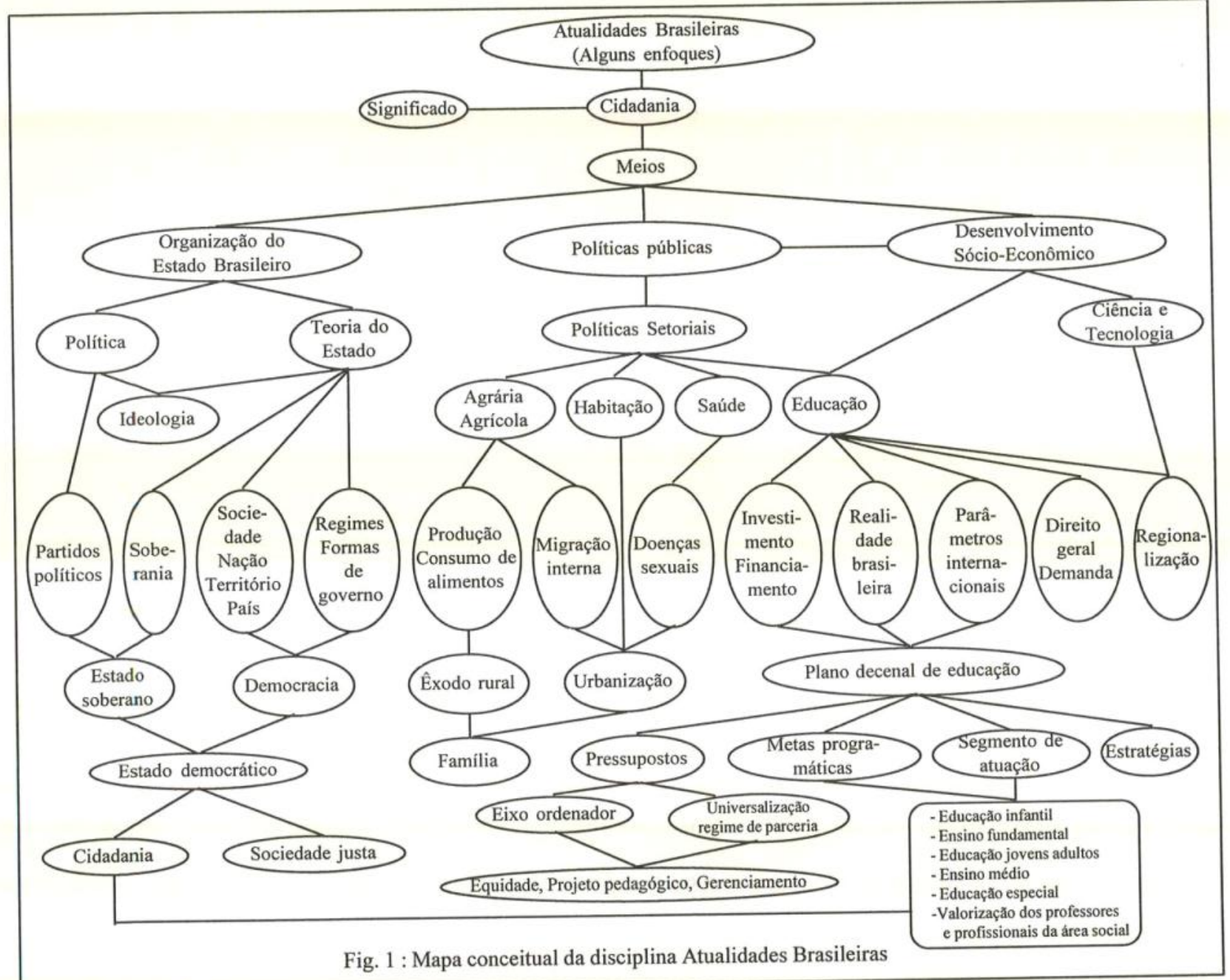


Educação deve ser feito mediante a abordagem dos indicadores dos seus pressupostos, suas estratégias e metas programáticas, em vista dos segmentos de atuação. Por sua vez, a conceituação dos pressupostos do Plano Decenal de Educação deve permitir a compreensão do significado de seu eixo ordenador (eqüidade, projeto pedagógico e gerenciamento) bem como possibilitar o entendimento da idéia (conceito) de universalização e do regime de parceria, princípios necessários para a efetivação de suas estratégias, através desse mesmo eixo ordenador, sobre os segmentos de atuação. Assim, na parte final desta unidade, após diferenciação dos segmentos de atuação, pela compreensão dos conceitos sobre educação infantil, ensino fundamental, educação de jovens e adultos, ensino médio, educação especial e valorização dos professores e profissionais da área social, se enfatizará a compreensão do Plano Decenal de Educação, como meio indispensável à construção da cidadania.

\section{QUARTA UNIDADE: DESENVOLVIMENTO SÓCIO- ECONÔMICO}

Nesta quarta unidade, pretende-se, igualmente, conceituar o desenvolvimento sócio-econômico enquanto meio de construção e atingimento da cidadania. Tal conceituação será pretendida no sentido de sua regionalização e diferenciação entre ciência e tecnologia, bem como sua relação com a educação (elemento da unidade anterior) para, finalmente, se obter a integralização com a idéia síntese de cidadania. 


\section{QUINTA UNIDADE: ESTADO DEMOCRÁTICO/ SOCIEDADE JUSTA}

Esta unidade estabelece uma relação biunívoca com as demais unidades da programação e permite, finalmente, reconciliar e integrar todos os conceitos anteriores, paulatinamente, construídos e sintetizados na compreensão dos conceitos significativos de Estado democrático, sociedade justa e de cidadania.

\section{O ASPECTO METODOLÓGICO DA PROGRAMAÇÃO}

No desenvolvimento da presente programação de "Atualidades Brasileiras", ênfase será dada à participação dos alunos na busca permanente de diferenciações progressivas dos conceitos, a partir do mais amplo, geral, inclusivo e de reconciliações integrativas (relacionamento e percepção de semelhanças e diferenças ou de incongruências-congruências entre os conceitos) pela comparação entre eles, a leitura de livros, comentários de notícias e artigos de jornais, exposição do professor, enquanto maneiras de provocar análise, críticas e sínteses.

A metodologia comporta discussão em grupo, estudo dirigido e interferência do professor para introdução e fechamento ou mesmo esclarecimento e enriquecimento, sempre que o assunto requeira conceitos prévios.

Como se pode depreender, a metodologia sugerida tem a preocupação de tornar o aluno participante ativo, para 
que ele próprio, progressivamente, vá construindo e organizando o seu conhecimento, de modo a dar-lhe características de unidade e globalidade.

\section{REFERÊNCIAS BIBLIOGRÁFICAS}

AEBLI, Hans. Didática psicológica: aplicação à didática da psicologia de Jean Piaget. São Paulo : Editora Nacional / Editora da USP, 1971.

ALVES, Júlia Falivene Nutrópolis. Cidadania e qualidade de vida. São Paulo : Moderna, 1992.

BRASIL, Lei Federal n ${ }^{\circ}$ 5.540/68. Reforma universitária.

BRASIL, Lei Federal n ${ }^{\circ} 7.853 / 89$. Direito das pessoas portadoras de deficiência.

BRASIL, Lei Federal n ${ }^{\circ} 8.069 / 90$. Estatuto da criança e o adolescente.

BRASIL, Lei Federal n ${ }^{\circ} 8.078 / 90$. Código de defesa do Consumidor.

BRASIL, MEC. Plano decenal de educação.

BRASIL. Linhas programáticas da educação brasileira. 1993/1994.

CARMO, Paulo Sérgio do. A ideologia do trabalho. São Paulo : Moderna, 1992. 
DALLARI, Sueli Gondolfi. A saúde do brasileiro. São Paulo: Moderna, 1987.

DEMO, Pedro. Cidadania menor. Petrópolis : Vozes, 1992.

ONU. Declaração universal dos direitos humanos, 1948.

DIAS, Maria Luiza. Vivendo em família. São Paulo : Moderna, 1992.

DIMENSTEIN, Gilberto. A Guerra dos meninos. São Paulo : Brasiliense, 1990.

DIMENSTEIN, Gilberto. Cidadão de papel. São Paulo : Ática, 1994.

DREXEL, John e IANNONE, Leila Rentróia. Criança e miséria: vida ou morte?. São Paulo: Moderna, 1993.

EISENSTEIN, Evelyn e SOUZA, Ronald Pagnocelli. Situações de riscos à saúde de crianças e adolescentes. Petrópolis : Vozes, 1993.

GIGOVATE, Flávio. Drogas: opção de perdedor. São Paulo: Moderna, 1992.

GIROUX, Henry. Teoria crítica e resistência em educação: para além das teorias de reprodução. Petrópolis : Vozes, 1983.

LUCKESI, Cipriano Carlos. et al. Fazer universidade: uma proposta metodológica. São Paulo : Cortez, 1991.

MARCONDES, Filho, Ciro. Violência política. São Paulo: Moderna, 1987. 
MARQUES, Heitor Romero. A família. S/d (mimeo).

MARQUES, Heitor Romero. Democracia. S/d (mimeo).

MARQUES, Heitor Romero. Ideologia. S/d (mimeo).

MARTINEZ, Paulo. Política, ciência, vivência e trapaça. São Paulo : Moderna, 199.

MINAYO, Maria Cecília de Souza (org). Raízes da fome. Petrópolis : Vozes / SASAE, 1987.

MOREIRA, Marco Aurélio. Mapas Conceituais como Instrumento para promover Diferenciação Conceitual Progressiva e a Reconciliação Integrativa. Ciência e Cultura, 32 (4) 474 - 9, abril, 1980.

MOREIRA, Marco A. e BUCHWEITZ, Bernardo. Mapas conceituais: instrumentos didáticos, de avaliação e de análise de currículo. São Paulo : Moraes, 1987.

PIAGET, Jean. Para onde vai a educação. Rio de Janeiro : Martins Fontes / UNESCO, 1978.

RESENDE, Ênio. Cidadania: o remédio para as doenças culturais brasileiras. São Paulo : Summus, 1993.

STRAHAM, Rudolf H. Subdesenvolvimento: por que somos tão pobres? São Paulo : Summus, 1993. 